\title{
The Reaction of Menadione with Haemoglobin
}

\author{
MECHANISM AND EFFECT OF SUPEROXIDE DISMUTASE
}

\author{
By CHRISTINE C. WINTERBOURN,* JOHN K. FRENCH* and RODNEY F. C. CLARIDGE $\dagger$ \\ *Department of Clinical Biochemistry, Christchurch Hospital, Christchurch, New Zealand, and \\ $\dagger$ Department of Chemistry, University of Canterbury, Christchurch, New Zealand
}

(Received 11 October 1978)

\begin{abstract}
1. Menadione was found to react with both the haem groups and the $\beta-93$ thiol groups of haemoglobin. 2. It oxidized the haem groups of oxyhaemoglobin, giving mainly methaemoglobin and a smaller amount of haemichrome. The reaction rate was decreased in the presence of catalase and markedly accelerated in the presence of superoxide dismutase. It is proposed that the overall reaction involves the initial reversible formation of methaemoglobin and the semiquinone, and that the effect of superoxide dismutase is to prevent the reverse reaction, by removing superoxide and hence the semiquinone via the equilibrium: semiquinone $+\mathrm{O}_{2} \rightleftharpoons$ quinone $+\mathrm{O}_{2}-$. E.s.r. evidence for the formation of the semiquinone and its reactions is presented. 3 . The reaction of menadione with the $\beta-93$ thiol groups of haemoglobin appeared to be similar to that with other thiols, forming the 3thioether derivative of menadione, but it was also accompanied by reduction of methaemoglobin. This reduction was prevented by superoxide dismutase, but appeared to be caused by the semiquinone radical, which was produced as an intermediate. 4. Reduced glutathione functioned only to a limited extent as a scavenger of the menadione semiquinone. Its main reaction was directly with menadione to form the thioether. Ascorbate was a more efficient scavenger, and accelerated the oxidation of oxyhaemoglobin by menadione. 5. The significance of these findings in relation to menadione-induced erythrocyte haemolysis is discussed.
\end{abstract}

The reaction of oxyhaemoglobin with menadione (2-methyl-1,4-naphthoquinone or vitamin $\mathrm{K}_{3}$ ) results in oxidation and precipitation of the haemoglobin (Kiese, 1974). In glucose 6-phosphate dehydrogenase deficiency or in the newborn, this can give rise to Heinz-body formation and haemolysis of the erythrocytes. This pattern of haemolysis is typical of a wide variety of redox drugs, which suggests that a product or products common to all drug-haemoglobin reactions are responsible. The main candidate that has been proposed for this role is $\mathrm{H}_{2} \mathrm{O}_{2}$ (Cohen \& Hochstein, 1964; Beutler, 1971). It is produced when all these drugs react with oxyhaemoglobin, and there is evidence that it cannot adequately be removed when the pathway for GSH regeneration is defective (Mills, 1957; Cohen \& Hochstein, 1964). Superoxide production hias also been detected with a number of drugs, including menadione (Goldberg \& Stern, 1975, $1976 a, b, 1977)$, and its involvement in haemolysis speculated upon. It seems likely, however, that these reactions have another common feature that could contribute to haemolysis, and this is the production of drug free radicals as intermediates. With acetylphenylhydrazine, production of the acetylphenylhydrazyl radical has been demonstrated, and it appears to make a major contribution to the haemo-

Abbreviation used: GSH, reduced glutathione. globin breakdown (French et al., 1978). In the present paper we show that the reaction of haemoglobin with menadione also produces the semiquinone free radical.

Another potential contributor to haemolysis by menadione is its ability to react with thiols, including $\mathrm{GSH}$, to form a thioether addition product at the 3-position (Fieser \& Fieser, 1953). This reaction is not readily reversible, and should result in depletion of erythrocyte GSH concentrations. Menadione has also been shown to react with thiol groups in proteins such as papain and serum albumin (Nakai \& Hase, 1968). As far as we are aware, however, little consideration has been given to the likelihood of a similar reaction with the exposed $\beta-93$ thiol groups of haemoglobin, or to its consequences.

The purpose of the present study is to show that menadione reacts reversibly with the haem groups of oxyhaemoglobin to form methaemoglobin and the semiquinone, as well as with the $\beta-93$ thiol groups to form an addition product, and to explain why the reaction is markedly accelerated in the presence of superoxide dismutase.

\section{Experimental}

Methods for the purification of human oxyhaemoglobin, preparation of methaemoglobin and spectro- 
photometric analysis of haemoglobin mixtures are described by French et al. (1978). Reactions between menadione and oxyhaemoglobin were carried out in phosphate buffer, $\mathrm{pH} 7.4$, prepared from $0.067 \mathrm{M}$ $\mathrm{Na}_{2} \mathrm{HPO}_{4}$ and $0.067 \mathrm{M}-\mathrm{KH}_{2} \mathrm{PO}_{4}$, containing $0.5 \mathrm{M}-$ propan-2-ol and 0.1 mM-EDTA, and saturated with air unless otherwise stated. With 1,4-naphthoquinone-2-sulphonate, no propan-2-ol was required. Reactions of deoxyhaemoglobin were carried out in evacuated tonometers. The quinone solution was carefully introduced through the side arm after evacuation. Semiquinone radicals produced during the reaction of oxyhaemoglobin with menadione were detected by e.s.r. spectroscopy with a Varian E12 spectrometer and $10 \mathrm{kHz}$ modulation.

Semiquinone radicals were generated either by irradiating $\mathrm{N}_{2}$-bubbled solutions of the quinone $(2 \mathrm{mM})$ with $356 \mathrm{~nm}$ light or by heating at $40^{\circ} \mathrm{C}$ under $\mathrm{N}_{2}$, each for about $10 \mathrm{~min}$. U.v. irradiation produced a much higher radical yield, and with menadione was the preferred method. Subsequent reactions of the radicals were studied under $N_{2}$. The $\beta-93$ thiol groups of haemoglobin were blocked by reaction with $10 \mathrm{~mol}$ of iodoacetamide/mol of haemoglobin for $1 \mathrm{~h}$ at $37^{\circ} \mathrm{C}$ in the dark. Unchanged iodoacetamide was removed on a column of Sephadex G-25. Free thiol groups were measured by reaction with 2,2'dithiobis-( 5 -nitropyridine) ( $33 \mu \mathrm{M}$, prepared by adding $0.02 \mathrm{ml}$ of a $5 \mathrm{~mm}$ stock solution in ethanol to $3 \mathrm{ml}$ of haemoglobin solution). Concentrations were calculated from absorbances at $386 \mathrm{~nm}$ (Grassetti \& Murray, 1969).

Menadione, catalase, superoxide dismutase, xanthine oxidase, GSH and sodium ascorbate were all obtained from the Sigma Chemical Co., St Louis, MO, U.S.A., 2,2'-dithiobis-(5-nitropyridine) was from the Aldrich Chemical Co., Milwaukee, WI, U.S.A., and 1,4-naphthoquinone-2-sulphonic acid was from Eastman Kodak Co., Rochıster, NY, U.S.A.

\section{Results}

Reaction of oxyhaemoglobin with menadione and effects of catalase and superoxide dismutase

Analysis of spectral changes during the reaction (Fig. 1) shows that oxyhaemoglobin was oxidized to methaemoglobin (causing an increase in $A_{630}$ ) and haemichrome (causing a decrease in the trough at $560 \mathrm{~nm}$ ), but very little choleglobin (which would have produced an increase in $A_{700}$ ). Continued incubation produced more methaemoglobin and haemichrome, and finally resulted in precipitation of the haemoglobin. The spectra shown in Fig. 1 were obtained in the presence of superoxide dismutase. As explained below, the enzyme increased the rate and extent of the reaction, but the nature of the

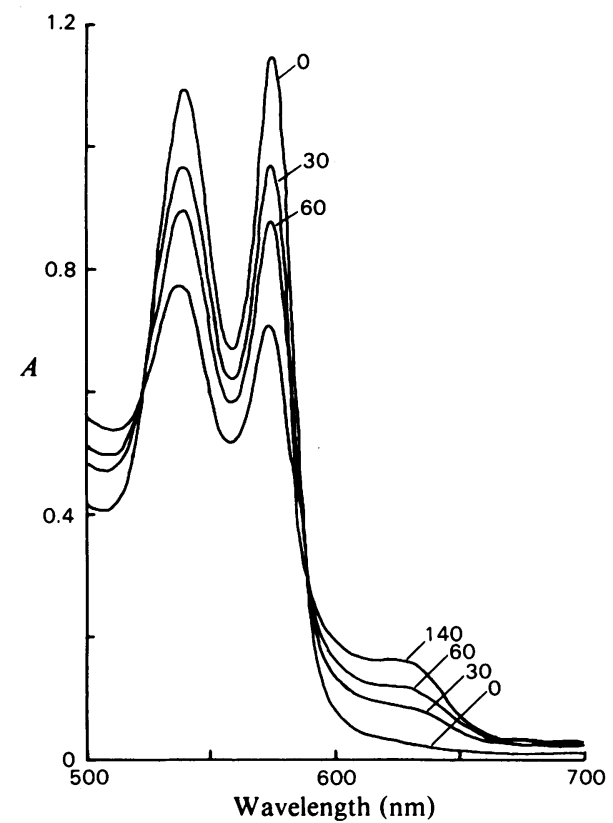

Fig. 1. Spectral changes during the oxidation of oxyhaemoglobin by menadione

The solution contained $20 \mu \mathrm{M}$-oxyhaemoglobin, 80 $\mu \mathrm{M}$-menadione and $3.3 \mu \mathrm{g}$ of superoxide dismutase $/ \mathrm{ml}$ in phosphate buffer, pH 7.4, containing EDTA and propan-2-ol. The reaction took place in the dark at 20 C. The numbers refer to the time in minutes from the commencement of the reaction.

spectral changes was not changed. The reaction was approximately one-third as fast in $\mathrm{O}_{2}$ as in air, and was considerably faster when the solution was bubbled with sufficient $\mathrm{N}_{2}$ to lower the $\mathrm{O}_{2}$ partial pressure without significantly deoxygenating the haemoglobin.

However, oxyhaemoglobin rather than deoxyhaemoglobin was the reactive species. No reaction between deoxyhaemoglobin and menadione was detectable, and inositol hexaphosphate $(2 \mathrm{~mol} / \mathrm{mol}$ of haemoglobin) had no effect on the rate of oxidation of oxyhaemoglobin.

Addition of catalase to remove $\mathrm{H}_{2} \mathrm{O}_{2}$, which is known to be produced during the reaction (Cohen \& Hochstein, 1964), slowed down the rate of oxidation of oxyhaemoglobin by menadione to about a half (Fig. 2). Superoxide is also produced from menadione and oxyhaemoglobin. Its removal by the addition of superoxide dismutase increased the rate of oxyhaemoglobin oxidation approximately 6-8-fold (Fig. 2). This dramatic increase in rate was evident in both the presence and the absence of catalase, and was of approximately the same order of magnitude in $\mathrm{O}_{2}$, air or decreased $\mathrm{O}_{2}$ partial pressure. Superoxide dis- 


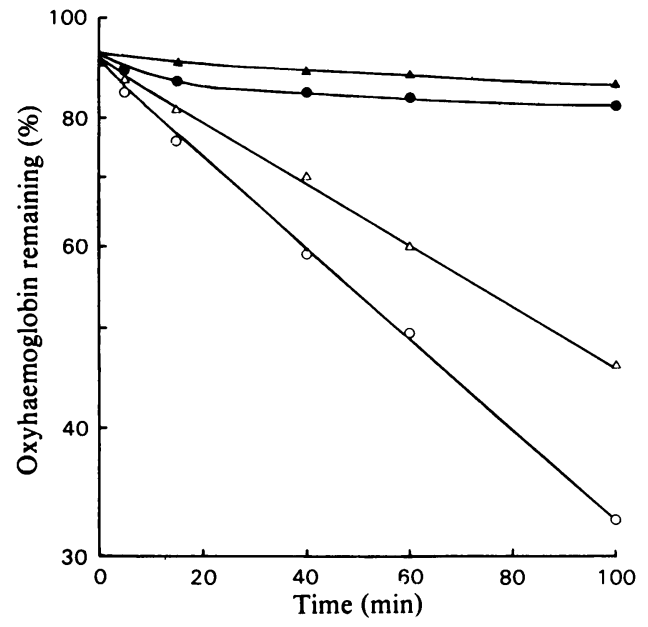

Fig. 2. Semi-logarithmic plot of the rate of oxidation of oxyhaemoglobin by menadione: effects of catalase and superoxide dismutase

Each solution contained $25 \mu \mathrm{M}$-oxyhaemoglobin, 200 $\mu \mathrm{M}$-menadione and, where indicated, $7 \mu \mathrm{g}$ of superoxide dismutase $/ \mathrm{ml}$ or $30 \mu \mathrm{g}$ of catalase $/ \mathrm{ml}$ in phosphate buffer, pH 7.4, containing EDTA and propan2-ol. Reactions took place in the dark at $20^{\circ} \mathrm{C}$. The concentrations of the different haemoglobin species were determined from the spectrum of each solution. The decrease in oxyhaemoglobin concentration was accompanied by a comparable rise in oxidation products. $\bullet$, No enzymes; $\Delta$, catalase; $\bigcirc$, superoxide dismutase; $\triangle$, both enzymes.

mutase, in addition to accelerating the reaction, also made it first-order with respect to oxyhaemoglobin. Superoxide generated exogenously from xanthine $(1 \mathrm{mM})$ and xanthine oxidase $(30 \mu \mathrm{g} / \mathrm{ml})$ in the presence of catalase had the opposite effect to superoxide dismutase, and virtually prevented oxyhaemoglobin oxidation. This effect was eliminated by adding superoxide dismutase.

In the presence of cyanide the spectral changes indicated that the product of haemoglobin oxidation was almost exclusively cyanmethaemoglobin, and the rate was 4-5-fold increased (Fig. 3). A semi-logarithmic plot of the data showed that the reaction was first-order with respect to oxyhaemoglobin. Cyanide alone at this concentration caused only a marginal increase in rate of haemoglobin autoxidation.

Exposure to light causes menadione to break down slowly, via the semiquinone, with the probable formation of the quinol. Solutions containing the quinol caused an initial rapid oxidation of oxyhaemoglobin, which then slowed down to the normal rate observed with fresh menadione solutions. Superoxide dismutase had very little effect on the initial fast reaction.

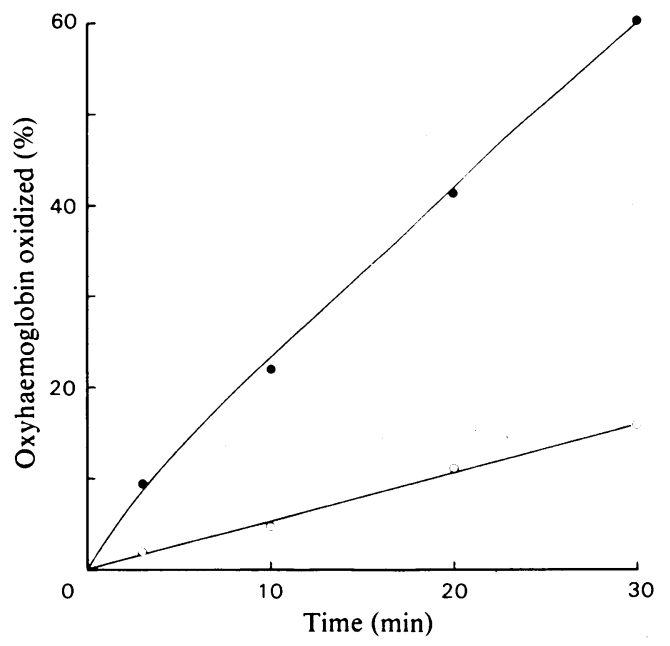

Fig. 3. Effect of cyanide on the rate of oxidation of oxyhaemoglobin by menadione

Each solution contained $10 \mu \mathrm{M}$-oxyhaemoglobin and $100 \mu \mathrm{M}$-menadione in phosphate buffer, $\mathrm{pH} 7.4$, containing EDTA and propan-2-ol. Reactions took place in the dark at $37^{\circ} \mathrm{C}$. $\circ$, No $\mathrm{KCN} ; \bullet$, plus $2.5 \mathrm{~mm}-$ $\mathrm{KCN}$.

\section{Reaction of methaemoglobin with menadione}

Menadione also reacted with methaemoglobin, reducing it to oxyhaemoglobin. The reaction was almost completely inhibited by superoxide dismutase. After reaction for $2 \frac{1}{2} \mathrm{~h}$ at $20^{\circ} \mathrm{C}$ with $100 \mu \mathrm{M}$-menadione, analysis of the absorbance changes showed that $10 \mu \mathrm{M}$-methaemoglobin was reduced to $85 \%$ oxyhaemoglobin, and in the presence of $6.7 \mu \mathrm{g}$ of superoxide dismutase $/ \mathrm{ml}$ the reaction was inhibited by $82 \%$. Methaemoglobin reduction occurred in the dark, and with freshly prepared menadione, and cannot therefore be attributed to the quinol or another product of the photochemical reduction of menadione. The reaction also took place in the absence of $\mathrm{O}_{2}$, when the product was deoxyhaemoglobin.

With mixtures of oxyhaemoglobin and methaemoglobin, menadione caused either a net reduction or oxidation, depending on the initial composition.

\section{Semiquinone radical as an intermediate}

Semiquinone intermediates have been proposed for the reaction of oxyhaemoglobin with quinones such as menadione (Goldberg \& Stern, 1976a; Augusto \& Cilento, 1975), but as far as we are aware they have not been observed directly. We were unable to obtain e.s.r. evidence for free-radical formation with menadione. However, 1,4-naphtho- 
quinone-2-sulphonate reacts similarly but very much more rapidly with oxyhaemoglobin, and when a solution of oxyhaemoglobin and 1,4-naphthoquinone2-sulphonate was warmed for about $10 \mathrm{~min}$ at $40^{\circ} \mathrm{C}$ it gave an e.s.r. signal identified as that of the semi-quinone of 1,4-naphthoquinone-2-sulphonate (Adams et al., 1958). The intensity of the signal was higher in $\mathbf{N}_{2}$-bubbled solutions and much lower if the reaction was carried out in an $\mathrm{O}_{2}$ atmosphere. In the presence of superoxide dismutase, although the oxyhaemoglobin was oxidized much more rapidly, at no stage of the reaction was the semiquinone detectable. When the reaction was carried out in the presence of methaemoglobin $(2 \mathrm{~mol} / \mathrm{mol}$ of oxyhaemoglobin), the e.s.r. signal was substantially decreased.

\section{Reactions of the semiquinone}

U.v. irradiation of menadione solutions under $\mathrm{N}_{2}$ produced the semiquinone, identified by its e.s.r. signal (Adams et al., 1958). The intensity of the signal decreased only slowly over $15 \mathrm{~min}$. It was not altered by the presence of superoxide dismutase $(20 \mu \mathrm{g} / \mathrm{ml})$. The signal rapidly disappeared on the addition of $\mathrm{O}_{2}$, as expected from the results obtained by Patel \& Willson (1973), who also showed that superoxide is a product. The semiquinone also rapidly disappeared on the addition of methaemoglobin $(50 \mu \mathrm{M})$, with deoxyhaemoglobin being produced. The reaction with methaemoglobin also took place in air, when the product was oxyhaemoglobin. The quinol that was present in menadione solutions left in the light also reduced methaemoglobin, but without producing a semiquinone signal. The radical signal also disappeared on the addition of oxyhaemoglobin $(100 \mu \mathrm{M})$, although it is not possible to say whether or not this was due to its reacting with the free $\mathrm{O}_{2}$ necessarily present in oxyhaemoglobin solutions. The radical did not oxidize the haem groups, however, as the product was deoxyhaemoglobin.

Addition of ascorbate $(5 \mathrm{~mm})$ caused the replacement of the e.s.r. signal of the semiquinone by the ascorbate signal, although $1 \mathrm{~mm}$-ascorbate had no effect. No reaction between ascorbate and menadione itself was detectable. GSH at $1 \mathrm{~mm}$ caused the gradual disappearance (over about $15 \mathrm{~min}$ ) of the menadione semiquinone signal. At $3 \mathrm{~mm}$ this disappearance was more rapid and the glutathione radical was detected. GSH, however, also reacted directly with menadione, yielding a yellow product but no detectable radical intermediates.

\section{Effect of free-radical scavengers on oxyhaemoglobin oxidation}

The previous results suggest that, in the reaction of oxyhaemoglobin with menadione, scavengers of the semiquinone should inhibit its reactions with methaemoglobin and with $\mathrm{O}_{2}$, thereby increasing the rate of oxyhaemoglobin oxidation and decreasing superoxide production. This effect on oxyhaemoglobin oxidation was found with ascorbate, which at a concentration of $100 \mu \mathrm{M}$ caused a several-fold increase in the rate of oxidation of $20 \mu \mathrm{M}$-oxyhaemoglobin by $200 \mu$ M-menadione. This increase was much greater than could be accounted for by the coupled oxidation of oxyhaemoglobin and ascorbate alone. However, with GSH, which can also react directly with menadione, there was an initial reduction of any preexisting methaemoglobin, followed by a slightly increased rate of loss of oxyhaemoglobin.

\section{Involvement of the $\beta-93$ thiol groups of haemoglobin}

Free $\beta-93$ thiol groups were essential for the reduction of methaemoglobin by menadione. When these groups were blocked with iodoacetamide, no reduction to oxyhaemoglobin occurred (Fig. 4), at least until after a much longer time, when slow reduction by a thiol-independent mechanism was evident. The slight increase in $A_{577}$ observed on first adding menadione, both in the presence of superoxide dismutase and with blocked methaemoglobin, appeared from the spectra of the solutions to arise from the formation of haemichrome rather than oxyhaemoglobin.

This thiol-dependent reduction of methaemoglobin also made a negative contribution to the rate of oxidation of oxyhaemoglobin by menadione. Blocked oxyhaemoglobin was oxidized more rapidly (Fig. 4). This effect was apparent only in the absence of superoxide dismutase; with superoxide dismutase present both blocked and unblocked oxyhaemoglobin were oxidized at the same rate.

Methaemoglobin reduction by menadione did not specifically require the participation of the $\beta-93$ thiol groups. With methaemoglobin blocked with iodoacetamide, GSH at a concentration equivalent to that of the $\beta-93$ thiol groups allowed the haem groups to be reduced by menadione at a similar rate to that found with native methaemoglobin.

The reaction of menadione with haemoglobin was accompanied by the gradual decrease in titratable thiol groups (Table 1). The decrease was approximately the same with oxyhaemoglobin and methaemoglobin, and slightly greater for both in the presence of superoxide dismutase. The product was indistinguishable from oxyhaemoglobin on cellulose acetate electrophoresis in the presence of sodium dodecyl sulphate. This indicates that the decrease in free thiol groups was not due to their forming interchain disulphide bonds, as this would produce $\beta$ chain dimers running in the 34000-mol.wt. position (Winterbourn \& Carrell, 1974). However, the u.v.absorption spectrum of the product was slightly 


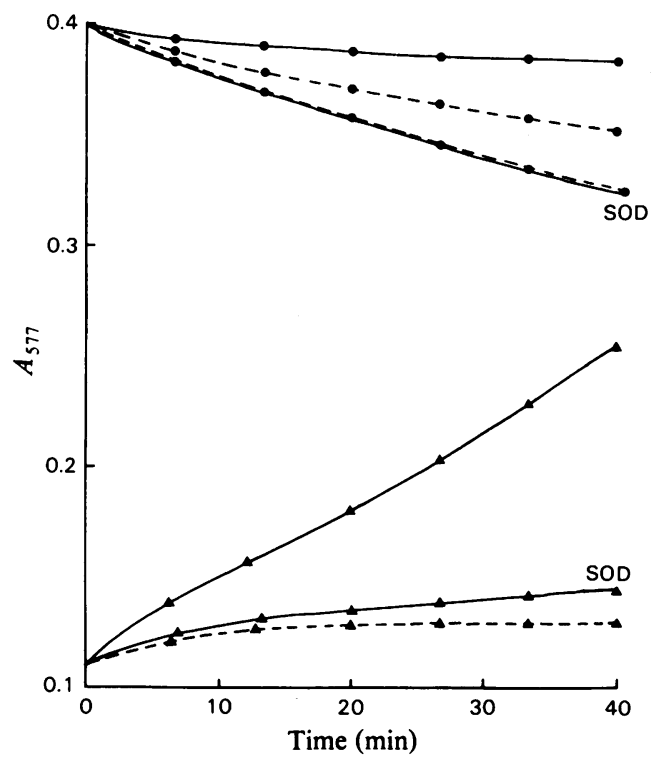

Fig. 4. Effects of blocking the $\beta-93$ thiol groups with iodoacetamide on the reaction of menadione with oxyhaemoglobin and methaemoglobin

Each solution contained $6 \mu \mathrm{M}$-haemoglobin, $100 \mu \mathrm{M}-$ menadione, and, where indicated, $6.7 \mu \mathrm{g}$ of superoxide dismutase $/ \mathrm{ml}$, in phosphate buffer, $\mathrm{pH7.4}$, containing EDTA and propan-2-ol. The reaction took place in the dark at $20^{\circ} \mathrm{C}$ and was followed by continuously recording $A_{577}$. An increase in $A_{577}$ primarily represents conversion of methaemoglobin into oxyhaemoglobin, although any haemichrome formation will also contribute to the increase. Conversely, a decrease in $A_{577}$ represents primarily conversion of oxyhaemoglobin into methaemoglobin. No free thiol groups were detectable in the haemoglobin after reaction with iodoacetamide. Oxyhaemoglobin; - -- $\bullet$, blocked haemoglobin; $\Delta-\Delta$, methaemoglobin; $\Delta---\Delta$, blocked methaemoglobin; SOD, plus superoxide dismutase.

different from that of an oxyhaemoglobin/methaemoglobin mixture of the same composition (Fig. 5). It showed increases in absorbance in similar positions and of similar intensity to the menadione maxima, and is compatible with the menadione being bound to the haemoglobin.

The stoicheiometry of the methaemoglobin reduction that accompanies this reaction was examined by using mixtures of methaemoglobin with free and iodoacetamide-blocked $\beta-93$ thiol groups. On increasing the proportions of unblocked haemoglobin, and so increasing the thiol, but not the haem, concentration, the rate of haem reduction increased almost in proportion to the thiol concentration (Fig. 6). As previously noted, after a period of no reaction slow reduction of fully blocked methaemo-
Table 1. Effect of menadione on the free thiol groups of haemoglobin

Oxyhaemoglobin or methaemoglobin $(80 \mu \mathrm{M})$ was left to react with menadione $(640 \mu \mathrm{M})$ at $20^{\circ} \mathrm{C}$ in phosphate buffer, pH7.4. Superoxide dismutase $(10 \mu \mathrm{g} / \mathrm{ml})$ was present where indicated. The haemoglobin was separated from excess reagent by passage through a Sephadex G-25 column before analysis. Analysis of a control oxyhaemoglobin solution gave a result of 1.9 thiol groups per tetramer.

Decrease in free thiol groups/haemoglobin tetramer

$\begin{array}{ccc}\text { Conditions } & 1 \mathrm{~h} & 1 \frac{1}{2} \mathrm{~h} \\ \text { Oxyhaemoglobin } & 0.5 & 0.9 \\ \text { +Superoxide dismutase } & 0.8 & 1.1 \\ \text { Methaemoglobin } & & 0.8 \\ \text { +Superoxide dismutase } & & 1.2\end{array}$

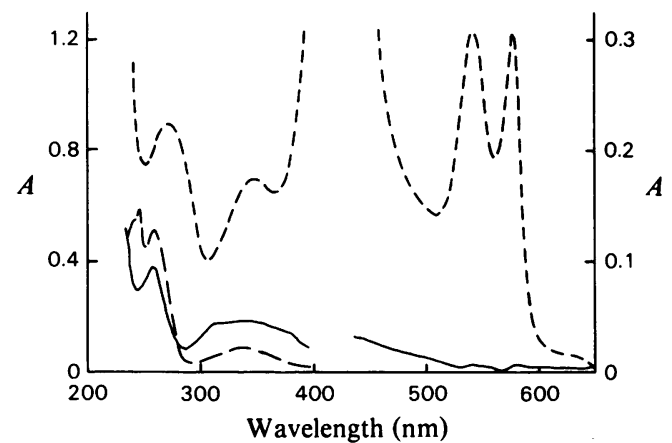

Fig. 5. Absorption spectrum of oxyhaemoglobin treated with menadione

----, $6.3 \mu \mathrm{M}-$ Oxyhaemoglobin treated with $1.2 \mathrm{~mm}$ menadione for $2 \mathrm{~h}$ at $20^{\circ} \mathrm{C}$ in the dark at $\mathrm{pH} 7.4$, and separated from excess menadione by passing through two columns of Sephadex G-25. An assay of free thiol groups gave $0.74 /$ haemoglobin tetramer. Difference spectrum of oxyhaemoglobin treated with menadione (as above) against a mixture of oxyhaemoglobin and methaemoglobin in the same proportions. $-1,7 \mu \mathrm{M}$-Menadione (approximately equivalent to the haemoglobin-bound menadione concentration if the blocked thiol groups have reacted with menadione).

globin occurred. It is particularly evident in this experiment because of the high menadione concentration used. At each concentration of free thiol groups a point (marked with an arrow) was reached when the rate of reduction was equal to that of blocked methaemoglobin, indicating that the number of haem groups reduced per thiol group was finite. The approximate amount of thiol-dependent reduction was calculated, on the assumption that oxyhaemo- 


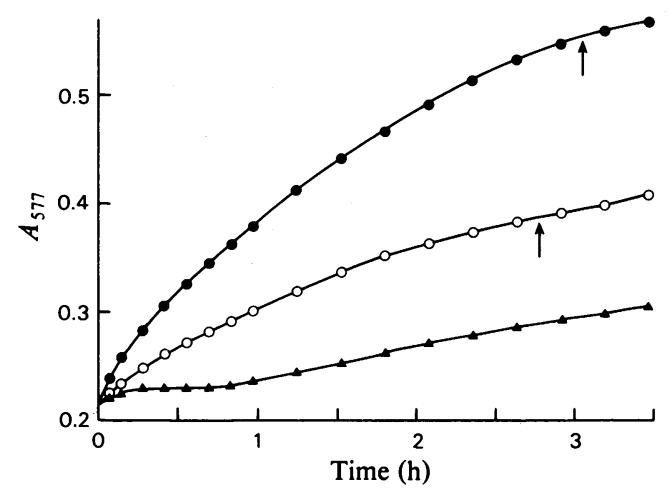

Fig. 6. Effect of varying the proportions of free and iodoacetamide-blocked $\beta-93$ thiol groups on the reduction of methaemoglobin by menadione

Mixtures of normal and blocked methaemoglobin (total concn. $12 \mu \mathrm{M}$ ) were treated with $480 \mu \mathrm{M}$-menadione at $20^{\circ} \mathrm{C}$ in the dark, in phosphate buffer, $\mathrm{pH}$ 7.4, containing EDTA and propan-2-ol. See the legend to Fig. 4 for explanation of absorbance changes. $\triangle$, No free thiol groups; $\bigcirc, 0.55$ free thiol groups/haemoglobin tetramer; $\bullet, 1.3$ free thiol groups/ haemoglobin tetramer. The arrows mark the point on each curve at which the slope became that of the control (with no free thiol groups), i.e. when there was no further thiol-dependent haem reduction.

globin is the only product, from the absorbance change:

Haem groups reduced/thiol group $=$

$$
\frac{A_{577} \text { (at arrow) }-A_{577} \text { (control) } \times 4}{47.5 \times \text { concn. of thiol groups }}
$$

47.5 being the difference in extinction coefficient of oxyhaemoglobin and methaemoglobin at $577 \mathrm{~nm}$.

(The error introduced by the assumption is slight, as less than $10 \%$ of the product would be haemichrome.) This value increased slightly as the ratio of haem to free thiol groups increased, but always lay within the range $1.5-1.8$.

\section{Comparison of 1,4-naphthoquinone-2-sulphonate with menadione}

1,4-Naphthoquinone-2-sulphonate reacted with oxyhaemoglobin very much more rapidly than did menadione, but the products, and the effects of catalase and superoxide dismutase on each, were similar. However, there were some notable differences. 1,4-Naphthoquinone-2-sulphonate $(120 \mu \mathrm{M}$ at room temperature) directly oxidized deoxyhaemoglobin $(20 \mu \mathrm{M})$. Within $5 \mathrm{~min} 30 \%$ of the haemoglobin was oxidized to methaemoglobin, and then there was a much slower reduction back to deoxyhaemoglobin.

Whereas the breakdown of menadione in solution is light-dependent, autoreduction of 1,4-naphtho- quinone-2-sulphonate solutions occurred in the dark, and was unaffected by $\mathrm{O}_{2}, \mathrm{~N}_{2}$ or superoxide dismutase. Reduced derivatives, particularly the quinol, would therefore arise via this mechanism in any reaction of 1,4-naphthoquinone-2-sulphonate.

Methaemoglobin reacted with the quinol of 1,4-naphthoquinone-2-sulphonate in preference to the semiquinone, to produce the semiquinone, detected by its e.s.r. signal, and oxyhaemoglobin. Methaemoglobin added in excess of the quinol reacted with the semiquinone. Ascorbate reacted with 1,4-naphthoquinone-2-sulphonate directly to give the semiquinone, and only when present in excess was the e.s.r. signal of the semiquinone replaced by that of the ascorbate radical. The reaction of GSH with naphthoquinone-2-sulphonate was similar to that with menadione, but very much faster.

\section{Comparison of erythrocyte lysates with purified haemoglobin solutions}

Since the reaction of oxyhaemoglobin with menadione is influenced by catalase, GSH and in particular superoxide dismutase, an assessment of the overall significance of these effects in the erythrocyte was made by comparing the rates of oxidation of purified oxyhaemoglobin and oxyhaemoglobin in a fresh erythrocyte lysate. The constituents of the lysate were found to exhibit an acceleratory effect, and increased the rate of oxyhaemoglobin oxidation to about two-thirds of that observed in the presence of excess superoxide dismutase and catalase. Neither the addition of glucose $(2 \mathrm{mg} / \mathrm{ml})$ nor 10 days' storage of the haemolysate at $4^{\circ} \mathrm{C}$ made any difference to the rate of oxidation. Haemoglobin precipitation also occurred much earlier in the lysate than in purified solution.

\section{Discussion}

The reaction between menadione and haemoglobin is obviously complex, with a number of steps involving derivatives of each component at different stages of oxidation. In order to determine the mechanism, we have investigated what reactions are likely to occur between these various intermediates. In previous studies (Goldberg \& Stern, 1976b) problems associated with the limited solubility of menadione in water have been overcome by using 1,4-naphthoquinone-2-sulphonate as a substitute. However, we have observed a number of behavioural differences between the two related quinones. With oxyhaemoglobin, a much faster reaction with 1,4-naphthoquinone-2-sulphonate appears to have been the main difference, but deoxyhaemoglobin reacted readily with 1,4-naphthoquinone-2-sulphonate and not at all with menadione. Other differences in behaviour reflected a greater stability of the semiquinone of 1,4-naphthoquinone-2-sulphonate. Methaemoglobin 
reacted preferentially with the semiquinone of menadione, but with the quinol of 1,4-naphthoquinone-2-sulphonate, producing the semiquinone. Ascorbate, although a scavenger of the menadione radical, reacted with1, 4-naphthoquinone-2-sulphonate to produce the semiquinone. These differences are not unexpected in view of the differences in redox potential for the two one-electron reduction steps for the two quinones (Ilan et al., 1976; Patel \& Willson, 1973), and the enhanced reactivity that would be conveyed by the sulphonate group of 1,4-naphthoquinone-2-sulphonate. However, they can influence the overall outcome, particularly of reactions involving a number of oxidation-reduction steps, and conclusions based on the behaviour of 1,4naphthoquinone-2-sulphonate will not necessarily be applicable to menadione.

Wherever possible, therefore, the reactions of menadione itself were studied. The one exception was when e.s.r. was used to detect the semiquinone radical. 1,4-Naphthoquinone-2-sulphonate reacted very rapidly with oxyhaemoglobin, and gave a readily detectable semiquinone signal. The reaction with menadione was much slower, and it was therefore unlikely to build up a detectable radical concentration. However, from the similarity of the overall reactions of menadione and 1,4-naphthoquinone-2-sulphonate with oxyhaemoglobin it would be expected that the semiquinone is produced with both.

Menadione appears to react with haemoglobin in two different ways. Firstly, there is direct oxidation of oxyhaemoglobin to methaemoglobin, and, secondly, an addition reaction with the $\beta-93$ thiol groups giving concomitant reduction of the haem groups. We propose that the reaction with oxyhaemoglobin involves a one-electron reduction of menadione to the semiquinone, and is reversible:

$$
\mathrm{HbO}_{2}+\mathrm{Q} \rightleftharpoons \mathrm{Hb}^{3+}+\mathrm{O}_{2}+\mathrm{SQ}^{\cdot-}
$$

where $\mathrm{HbO}_{2}$ is oxyhaemoglobin, $\mathrm{Hb}^{3+}$ is methaemoglobin, $\mathrm{Q}$ is menadione and $\mathrm{SQ}^{--}$is menadione semiquinone. Our e.s.r. evidence with 1,4-naphthoquinone-2-sulphonate favours a semiquinone intermediate, and several factors point to reaction (1) being reversible. Firstly, the semiquinone radical very rapidly reduced methaemoglobin to oxyhaemoglobin. Secondly, the rate of oxidation of oxyhaemoglobin by menadione was decreased when additional methaemoglobin was present and increased when cyanide was present to convert the methaemoglobin formed into cyanmethaemoglobin and thus prevent the reverse reaction. The first-order kinetics observed in the presence of cyanide can also be attributed to the elimination of product inhibition.

Menadione appears to react with the $\beta-93$ thiol groups of haemoglobin in the same way as with other thiols that form a 3-thioether derivative (Fieser \&
Fieser, 1953). A similar reaction with haemoglobin is indicated by the blockage of the $\beta-93$ thiol groups without the formation of disulphides and the apparent menadione contribution to the u.v.-absorption spectrum. The reaction also caused the reduction of methaemoglobin. Internal electron transfer from the $\beta-93$ thiol groups to the haem groups must be excluded, because of the stoicheiometry of more than 1 haem group reduced per thiol group, and also the ability of GSH to substitute for the haemoglobin thiol groups. The reaction was inhibited by superoxide dismutase, but it can only be concluded from this that superoxide was produced, and not that it was responsible for the methaemoglobin reduction. This reaction is known to occur, but under most conditions it does not compete favourably with spontaneous dismutation of superoxide (Sutton et al., 1976), and it could not be responsible for the rate and extent of methaemoglobin reduction in the current study. The most likely explanation is that the reaction between the haemoglobin thiol groups and menadione produces the semiquinone, which is responsible for the methaemoglobin reduction (or the decreased rate of oxidation when oxyhaemoglobin is the starting material). The semiquinone has been shown to reduce methaemoglobin readily, and this explanation also accounts for the inhibitory effect of superoxide dismutase. Other studies (Winterbourn et al., 1978) have shown that superoxide dismutase, although specific for superoxide, can inhibit the reaction of the menadione semiquinone with methaemoglobin because the semiquinone produces superoxide through a reversible reaction with $\mathrm{O}_{2}$ :

$$
\begin{gathered}
\mathrm{SQ}^{\cdot-}+\mathrm{O}_{2} \rightleftharpoons \mathrm{Q}+\mathrm{O}_{2} \cdot- \\
2 \mathrm{O}_{2}^{-}+2 \mathrm{H}^{+} \underset{\text { dismutase }}{\stackrel{\text { Superoxide }}{\longrightarrow}} \mathrm{O}_{2}+\mathrm{H}_{2} \mathrm{O}_{2}
\end{gathered}
$$

By removing superoxide via reaction (3), the dismutase has the effect of displacing reaction (2) to the right, allowing $\mathrm{O}_{2}$ to compete much more favourably for the semiquinone and inhibiting its other reactions.

The finding of between 1 and 2 haem groups reduced per thiol group is compatible with the following stoicheiometry for the overall reaction:<smiles>[R9][13c]1ccc2c(c1)C(=O)C(C)=CC2=O</smiles><smiles>[R7]C1=C(C)C(=O)c2ccccc2C1=O</smiles> 
The semiquinone must be an intermediate, causing the reduction of the haem groups, and competing reactions would account for the yield of reduced haem groups being slightly less than 2 .

The acceleratory effect of superoxide dismutase on the oxidation of oxyhaemoglobin by menadione can also be explained by its ability to inhibit reactions of the menadione semiquinone. In this case, superoxide dismutase, by facilitating the removal of the semiquinone via reactions (2) and (3), would effectively prevent the reverse of reaction (1). This would explain the observed increase in rate of oxyhaemoglobin oxidation and the first-order kinetics. This explanation appears to be much more satisfactory than those suggested by other investigators. Augusto \& Cilento (1975) have studied the reaction of haemoglobin with quinols, and on the basis of observations by Rapp et al. (1973) suggested that superoxide dismutase may act by stabilizing the semiquinone radicals. However, our e.s.r. studies showed that the enzyme (in air) eliminated the radical signal and do not support this interpretation. The absence of any effect of superoxide dismutase on the e.s.r. signal of the menadione radical under $\mathrm{N}_{2}$ also eliminates the possibility of a direct reaction between the enzyme and the semiquinone. Goldberg \& Stern $(1976 a)$ have postulated that the effect of superoxide dismutase is explained by its causing an increase in $\mathrm{H}_{2} \mathrm{O}_{2}$ production, but this interpretation is incompatible with our observation that superoxide dismutase still accelerates the reaction in the presence of catalase.

It must be concluded from the experiments showing no reaction between menadione and deoxyhaemoglobin, and no effect of inositol hexaphosphate on the reaction with oxyhaemoglobin, that oxyhaemoglobin rather than deoxyhaemoglobin is the reactive species. This disagrees with the mechanism proposed by Goldberg \& Stern (1976a), but their conclusions were based on experiments in which inositol hexaphosphate was found to enhance the rate, but when present at 20 times the haemoglobin concentration, compared with our 2 -fold excess. As inositol hexaphosphate can bind to haemoglobin other than at the 2,3-bisphosphoglycerate-binding site, effects of such an excess cannot necessarily be attributed to its altering the deoxy-oxy conformational equilibrium. The requirement for oxyhaemoglobin suggests that the haemoglobin-bound $\mathrm{O}_{2}$ is involved in the reduction of menadione. This seems reasonable when oxyhaemoglobin is viewed as a superoxo-ferrihaem compound, $\mathrm{Hb}-\mathrm{Fe}^{3+} \mathrm{O}_{2}{ }^{-}$[for which there is much evidence (Collman et al., 1976)], in which the bound superoxide is activated by association with the haem group. The reaction can then be considered as a reduction by the bound superoxide (which is oxidized to $\mathrm{O}_{2}$ ). This compares with the reaction of oxyhaemoglobin with acetylphenylhydrazine, in which the bound superoxide acts as an oxidizing agent and is reduced to $\mathrm{H}_{2} \mathrm{O}_{2}$ (French et al., 1978).

The inhibitory effect of $\mathrm{O}_{2}$ on oxyhaemoglobin oxidation by menadione cannot therefore be explained in terms of deoxyhaemoglobin being the reactive species. Neither can it be attributed to increased $\mathrm{O}_{2}$ partial pressure favouring the removal of the semiquinone via reaction (2). However, since $\mathrm{O}_{2}$ is produced reversibly from the reaction between menadione and oxyhaemoglobin (reaction 1), the most likely explanation is that this reaction is influenced by the $\mathrm{O}_{2}$ concentration and is subject to product inhibition.

Menadione oxidized oxyhaemoglobin to mainly methaemoglobin, but the spectral changes showed that haemichrome also gradually accumulated. However, there was very little choleglobin formation. This contrasts with the reaction between haemoglobin and reducing agents such as acetylphenylhydrazine, when the denatured products are both choleglobin and haemichrome (French et al., 1978). With acetylphenylhydrazine the initial step involves reduction of the haemoglobin-bound oxygen to produce a methaemoglobin- $\mathrm{H}_{2} \mathrm{O}_{2}$ complex, and choleglobin is thought to be formed from this complex by internal peroxidation of the porphyrin ring (French et al., 1978; Brown, 1976). However, with menadione the initial step involves oxidation of the oxyhaemoglobin and the complex is not formed. In this reaction, the $\mathrm{H}_{2} \mathrm{O}_{2}$ would arise from the dismutation of superoxide, and therefore be produced free in solution rather than in direct association with the haem groups. We have shown that this $\mathrm{H}_{2} \mathrm{O}_{2}$ does contribute to the overall oxyhaemoglobin oxidation, but very little of it gets to form a complex with methaemoglobin.

Although menadione is reduced by oxyhaemoglobin, whereas compounds such as acetylphenylhydrazine are oxidized, it appears that the initial step of both reactions involves the formation of a free radical. This suggests that, subsequent to this step, both reactions may follow a similar course, and indeed in the erythrocyte both are associated with haemoglobin breakdown and haemolysis. In a previous study of the reaction of haemoglobin with acetylphenylhydrazine, we have concluded that the acetylphenylhydrazyl radical plays a significant role in the haemoglobin and erythrocyte breakdown, and that an important protective function of the GSH in the cells is to act as a scavenger of such free radicals. Although consideration must be given to the different reactivities of different free radicals, and for example the acetylphenylhydrazyl radical should be much more reactive than semiquinones, it would seem likely that free-radical reactions are also significant in menadione-induced haemolysis. With purified haemoglobin, however, no obviously undesirable reactions of the menadione radical were 
detectable. Its major action was to reduce methaemoglobin. Also, the roles of GSH and ascorbate as free-radical scavengers are not as clear-cut as in the case of the acetylphenylhydrazyl radical. Although both were capable of scavenging the semiquinone, neither reaction was particularly avid and their most obvious effect was to accelerate the oxidation of oxyhaemoglobin. It may be that the main protection against menadione given by GSH is not against the radical. Rather, by reacting directly to form the thioether it may prevent a similar reaction from occurring with the $\beta-93$ thiol groups of haemoglobin. Prevention of menadione from reacting with membrane thiol groups may also be important. The work of Mezick et al. (1970) suggests that this reaction does occur, and is associated with haemolysis of the cells.

A more significant mechanism for the removal of the menadione semiquinone in the erythrocyte is likely to be mediated by superoxide dismutase. As we have shown (Winterbourn et al., 1978), by removing superoxide the enzyme favours the reaction of the radical with $\mathrm{O}_{2}$ and inhibits its other reactions. This mechanism appears to be operative in the erythrocyte, as evidenced by the much higher rate of oxidation of oxyhaemoglobin in lysed cells compared with pure solution. The effect was similar in fresh and stored cells and independent of glucose, which is compatible with its being due to superoxide dismutase, and not to GSH or another relatively unstable metabolite. Excess superoxide dismutase added to purified haemoglobin gave a higher rate of oxidation than in the haemolysate, suggesting that the activity of superoxide dismutase in the erythrocytes is less than that required for maximum effect. Although superoxide dismutase has an undesirable effect on the oxidation of oxyhaemoglobin by menadione, this is not necessarily true for the erythrocyte as a whole. The semiquinone may undergo more deleterious reactions with other cell constituents, and the enzyme may help to protect against these.

This work was supported by grants from the Medical Research Council of New Zealand and the Canterbury
Medical Research Foundation. The helpful advice of Dr. R. W. Carrell is gratefully acknowledged.

\section{References}

Adams, M., Blois, M. S. \& Sands, R. H. (1958) J. Chem. Phys. 28, 774-776

Augusto, O. \& Cilento, G. (1975) Arch. Biochem. Biophys. 168, 549-556

Beutler, E. (1971) Semin. Hematol. 8, 311-347

Brown, S. B. (1976) Biochem. J. 159, 23-27

Cohen, G. \& Hochstein, P. (1964) Biochemistry 3, 895-900

Collman, J. P., Brauman, J. I., Halbert, T. R., \& Suslick, K. S. (1976) Proc. Natl. Acad. Sci. U.S.A. 73, 3333-3337

Fieser, L. F. \& Fieser, M. (1953) Organic Chemistry, 2nd edn., p. 763, G. G. Harrap, London

French, J. K., Winterbourn, C. C. \& Carrell, R. W. (1978) Biochem. J. 171, 19-26

Goldberg, B. \& Stern, A. (1975) J. Biol. Chem. 250, 24012403

Goldberg, B. \& Stern, A. (1976a) Biochim. Biophys. Acta 437, 628-632

Goldberg, B. \& Stern, A. (1976b) J. Biol. Chem. 251, 64686470

Goldberg, B. \& Stern, A. (1977) Mol. Pharmacol. 13, 832839

Grassetti, D. R. \& Murray, J. F. (1969) J. Chromatogr. 41, $121-123$

Ilan, Y. A., Czapski, G. \& Meisel, D. (1976) Biochim. Biophys. Acta 430, 209-224

Kiese, M. (1974) Methemoglobinemia: A Comprehensive Treatise, p. 74, CRC Press, Cleveland

Mezick, J. A., Settlemire, C. T., Brierley, G. P., Barefield, K. P., Jensen, W. N. \& Cornwell, D. G. (1970) Biochim. Biophys. Acta 219, 361-371

Mills, G. C. (1957) J. Biol. Chem. 229, 189-197

Nakai, N. \& Hase, J. (1968) Chem. Pharm. Bull. (Tokyo) 16, 2339-2342

Patel, K. B. \& Willson, R. L. (1973) Faraday Soc. Trans. 69, 814-825

Rapp, U., Adams, W. C. \& Miller, R. W. (1973) Can. J. Biochem. 51, 158-171

Sutton, H. C., Roberts, P. B. \& Winterbourn, C. C. (1976) Biochem. J. 155, 503-510

Winterbourn, C. C. \& Carrell, R. W. (1974) J. Clin. Invest. 54, 678-689

Winterbourn, C. C., French, J. K. \& Claridge, R. F. C. (1978) FEBS Lett. 94, 269-272 